\title{
Vaginal birth after previous caesarean section in women at Al-Wahda hospital Derna, Libya
}

\author{
Soad Ajroud ${ }^{1}$, Raga A. Elzahaf ${ }^{2,3 *}$, Fawzia A. G. Arhaiam ${ }^{4}$
}

\author{
${ }^{1}$ Department of Obstetrics and Gynecology, Omar Elmukhtar University, Al-Wahda hospital, Derna, Libya \\ ${ }^{2}$ Departement of Public Health, College of Medical Technology, Derna, Libya \\ ${ }^{3}$ MENA Research Group, Libya \\ ${ }^{4}$ Department of Medical Care, College of Medical Technology, Derna, Libya
}

Received: 29 July 2021

Accepted: 11 October 2021

\author{
*Correspondence: \\ Dr. Raga A. Elzahaf, \\ E-mail: rarajaaelzahaf@gmail.com
}

Copyright: ( ) the author(s), publisher and licensee Medip Academy. This is an open-access article distributed under the terms of the Creative Commons Attribution Non-Commercial License, which permits unrestricted non-commercial use, distribution, and reproduction in any medium, provided the original work is properly cited.

\section{ABSTRACT}

Background: Vaginal birth after caesarean section is one strategy that has been developed to decrease the rate of caesarean section.

Methods: The prospective observational study was carried out over a period of 01 January 2017 to 31 December 2018 years. VBAC was routinely offered at Al-Wahda hospital Derna to women fulfilling the criteria for trial of scar, according to the hospital protocol.

Results: A total of 5018 deliveries took place in the study duration, there were $1039(20.7 \%)$ had previous one caesarean section, out of which $319(30.7 \%)$ were the number of underwent repeat caesarean section and $720(69.3 \%)$ were the number of VBAC. The indications for emergency repeat caesarean section at Al-Wahda hospital was (29.3\%) malpresentation, (24.45\%) FD, (13.47) postdate, (11.59) obstracted lab and abruptiopl (5.95\%). Anemia and difficult intubation were observed in repeated caesarean section.

Conclusions: This study concluded that there is a high chance of success in a trial of labor. These findings might help clinicians and women in the decision-making for the mode of delivery when it comes to pregnancy with a previous caesarean section. Women are explained about the option of trial of scar and told about the risk associated with a repeat CS, so many CSs can be avoided.

Keywords: Vaginal birth, Previous caesarean section, Derna, Libya

\section{INTRODUCTION}

Vaginal birth after caesarean section (VBAC) is one strategy that has been developed to decrease the rate of Caesarean section (CS). Pregnant women with one previous CS are faced with two delivery options: trail of scar or elective repeat CS. Successful of VBAC vary from one woman to other. However, it is possible for women to have vaginal delivery after a previous caesarean delivery. It has been shown 55-67\% of women, who had previously delivered through caesarean delivery, had successful vaginal delivery afterward. ${ }^{1,2}$ In recent meta-analysis conducted by Ellen and Eileen found that VBAC section may result in small increase in uterine rupture and fetal mortality rates compared with elective repeat $\mathrm{CS}$, while the successful VBAC may reduce the febrile morbidity, blood transfusion, and hysterectomy rates. ${ }^{3-5}$

In addition, VBAC increases the chance of succeeding vaginal birth and reduces the repeat $C S$ rate with subsequent postoperative morbidities. VBAC section has less complications and faster recovery compared with CS. Conflicting data exist concerning the safety of induction of labor in women with previous single CS. The greatest impact of failed trial of VBAC is emergency CS. ${ }^{6,7} \mathrm{CSs}$ are associated with more blood loss, more risk of bladder and 
ureteral injuries, postpartum infections, pulmonary embolisms, and more risks of neonatal respiratory complications (if performed before 39 weeks). ${ }^{6,8}$

In addition, multiple repeat $\mathrm{CSs}$ can lead to increased risk of maternal morbidity and mortality because of abnormal placental adherence and caesarean hysterectomy, which increases with each subsequent CS. ${ }^{9,10}$ Such complications are difficult to manage and can cause significant consequences and even maternal death. ${ }^{11}$

Therefore, VBAC reduce the consequences and complications of multiple caesarean sections especially for continuing fertility.

\section{Aim}

The aim of the study was to determine the success of vaginal birth after one previous SC, to know the cause of repeated $\mathrm{SC}$ and to evaluate the maternal and perinatal complications in both VBAC and SC.

\section{METHODS}

The prospective observational study was carried out over a period of 01 January 2017 to 31 December 2018 years. VBAC was routinely offered at Al-Wahda hospital Derna to women fulfilling the criteria for trail of scar according to the hospital protocol.

All the women admitted with previous one caesarean section during the study period were included in the study. Complete history including indication of previous one caesarean section, intra and postoperative complications of previous one caesarean section. Eligibility criteria for VBAC include previous one CS are no absolute indication for SC as contracted pelvis, placenta previae or malpresentation, average fetal weight with vertex presentation.

\section{RESULTS}

A total of 5018 deliveries took place in the study duration, 1039 had previous CS, out of which 319 (30.7\%) were the number of CS (underwent repeat caesarean section), 142 were emergency and 177 elective caesarean section and
$720(69.3 \%)$ were the number of VBAC. The mean age of the women delivering was $30.8 \pm 5.6$ years; of the women delivering by caesarean was $31.1 \pm 5.9$ years and by vaginal delivery was $30.5 \pm 5.3$. Majority of women $(69.0 \%)$ were multigravida and $78.8 \%$ of the women were parity from 1 to 3 .

The mean gestational age of the women delivering VBAC was $36.6 \pm 4.6$ weeks and the women delivering by repeat caesarean section was $37.9 \pm 4.7$ weeks. The average duration of hospital stay for women having a successful VBAC was lower $(1.18 \pm 0.52$ days) than women who required a repeat $\mathrm{CS}(3.05 \pm 1.55$ days) (Table 1$)$.

The indications for emergency repeat caesarean section at Al-Wahda hospital was $211(29.3 \%)$ malpresentation, 78 (24.45\%) Fetal distress (FD), 43 (13.47) post-date, 37 (11.59\%) obstracted lab and abruptiopl 19 (5.95\%). However, indications for previous caesarean section have been analyzed in several broad categories namely: FD 300 (41\%), malpresentation 211(29.3\%), obstracted lab 45 $(6.3 \%)$, primary infertility $25(3.5 \%)$ and severe preeclampsia/eclampsia 20 (2.8\%) (Table 2).

A total of $37(78.7 \%)$ neonates were admitted to the neonatal intensive care unit following CS delivery and 10 (21.3\%) were admitted following VBAC. There were statistical differences between caesarean section and vaginal birth $\left(\mathrm{X}^{2}=24.50, \mathrm{p}=0.001\right)$.

The factors associated with cause of admission to neonatal intensive care unit among caesarean section delivery and VBAC, as reported in Table 3, were $23(48.9 \%)$ Respiratory distress syndrome (RDS), 12(25.5\%) Infant of diabetic mother (IDM) and birth asphyxia 3(6.4\%). However, the most common cause of admission among caesarean section delivery was RDS, IDM and birth asphyxia and the most common cause of admission among VBAC case was RDS. Complications were observed in $5.9 \%(\mathrm{~N}=24)$ of the vaginal birth cases, and $8.8 \%(\mathrm{~N}=28)$ of the caesarean section cases. This difference was not significant $(\mathrm{p}=0.192)$ (Table 4$)$.

A total of $8(1.1 \%)$ cases of congenital anomalies were recorded, the most common anomalies was club foot 2 $(25 \%)$ and neural tube defect $2(25 \%)$ (Table 5).

Table 1: Maternal characteristics on admission.

\begin{tabular}{|c|c|c|c|c|c|c|c|c|c|}
\hline \multirow[t]{2}{*}{ Characteristics } & \multicolumn{2}{|c|}{$\begin{array}{l}\text { Successful } \\
\text { VBAC }\end{array}$} & \multirow[t]{2}{*}{ Mean \pm SD } & \multicolumn{2}{|c|}{$\begin{array}{l}\text { Unsuccessful } \\
\text { VBAC }\end{array}$} & \multirow[t]{2}{*}{ Mean \pm SD } & \multirow[t]{2}{*}{ Total } & \multirow[t]{2}{*}{$x^{2}$} & \multirow[t]{2}{*}{ P value } \\
\hline & $\mathbf{N}$ & $\%$ & & $\mathbf{N}$ & $\%$ & & & & \\
\hline \multicolumn{10}{|l|}{ Age (years) } \\
\hline Less than 25 & 81 & 56.3 & \multirow{4}{*}{$30.6 \pm 5.34$} & 63 & 43.8 & \multirow{4}{*}{$31.12 \pm 5.97$} & 144 & \multirow{4}{*}{5.52} & \multirow{4}{*}{0.137} \\
\hline $25-30$ & 128 & 56.9 & & 97 & 43.1 & & 225 & & \\
\hline $31-35$ & 114 & 60.3 & & 75 & 39.7 & & 189 & & \\
\hline 36 and more & 78 & 48.1 & & 84 & 51.9 & & 162 & & \\
\hline \multicolumn{10}{|l|}{ Parity } \\
\hline $1-3$ & 299 & 52.7 & \multirow{2}{*}{$2.4 \pm 1.16$} & 268 & 47.3 & & 567 & \multirow{2}{*}{11.9} & \multirow{2}{*}{0.003} \\
\hline $4-6$ & 96 & 68.6 & & 44 & 31.4 & $1.76 \pm 1.13$ & 140 & & \\
\hline
\end{tabular}




\begin{tabular}{|c|c|c|c|c|c|c|c|c|c|}
\hline \multirow[t]{2}{*}{ Characteristics } & \multicolumn{2}{|c|}{$\begin{array}{l}\text { Successful } \\
\text { VBAC }\end{array}$} & \multirow[t]{2}{*}{ Mean \pm SD } & \multicolumn{2}{|c|}{$\begin{array}{l}\text { Unsuccessful } \\
\text { VBAC }\end{array}$} & \multirow[t]{2}{*}{ Mean \pm SD } & \multirow[t]{2}{*}{ Total } & \multirow[t]{2}{*}{$x^{2}$} & \multirow[t]{2}{*}{ P valuc } \\
\hline & $\mathbf{N}$ & $\%$ & & $\mathbf{N}$ & $\%$ & & & & \\
\hline More than 7 & 6 & 46.2 & & 7 & 53.8 & & 13 & & \\
\hline \multicolumn{10}{|l|}{ Gravida } \\
\hline Multigravida & 253 & 50.9 & \multirow[b]{2}{*}{$3.9 \pm 2.24$} & 244 & 49.1 & \multirow{2}{*}{$3.79 \pm 1.75$} & 497 & \multirow[b]{2}{*}{14.9} & \multirow[b]{2}{*}{0.001} \\
\hline $\begin{array}{l}\text { Grandmulti- } \\
\text { gravida }\end{array}$ & 148 & 66.4 & & 75 & 33.6 & & 223 & & \\
\hline \multicolumn{10}{|l|}{ GA } \\
\hline Pre-term (PT) & 13 & 34.2 & \multirow{3}{*}{$36.6 \pm 4.6$} & 25 & 65.8 & \multirow{3}{*}{$37.9 \pm 4.7$} & 38 & \multirow{3}{*}{20.4} & \multirow{3}{*}{0.001} \\
\hline Term (T) & 336 & 60.1 & & 223 & 39.9 & & 559 & & \\
\hline Post-date (PD) & 52 & 42.3 & & 71 & 57.7 & & 123 & & \\
\hline \multicolumn{10}{|c|}{ Birth weight (g) } \\
\hline Less than 2500 & 21 & 41.2 & \multirow{3}{*}{$3365.5 \pm 559$} & 30 & 58.8 & \multirow{3}{*}{$\begin{array}{l}3334.2 \pm 63 \\
2\end{array}$} & 51 & \multirow{3}{*}{4.74} & \multirow{3}{*}{0.930} \\
\hline $2500-3500$ & 231 & 57.2 & & 173 & 42.8 & & 404 & & \\
\hline More than 3500 & 149 & 56.2 & & 116 & 43.8 & & 265 & & \\
\hline \multicolumn{10}{|l|}{ Abortion } \\
\hline No & 254 & 55.7 & \multirow{2}{*}{$1.5 \pm 0.83$} & 202 & 44.3 & \multirow{2}{*}{$1.61 \pm 1.01$} & 456 & \multirow{2}{*}{0.99} & \multirow{2}{*}{0.529} \\
\hline Yes & 147 & 55.7 & & 117 & 44.3 & & 264 & & \\
\hline \multicolumn{10}{|c|}{ Duration of hospital stay } \\
\hline $1-2$ & 391 & 74.8 & \multirow{3}{*}{$1.18 \pm 0.52$} & 132 & 25.2 & \multirow{3}{*}{$3.05 \pm 1.55$} & 523 & \multirow{3}{*}{281.8} & \multirow{3}{*}{0.001} \\
\hline $3-5$ & 10 & 5.7 & & 165 & 94.3 & & 175 & & \\
\hline 6 and more & 0 & 0 & & 22 & 100 & & 22 & & \\
\hline
\end{tabular}

Table 2: Indications for previous caesarean section and current caesarean.

\begin{tabular}{|lllll|}
\hline & \multicolumn{2}{c}{ Previous caesarean } & \multicolumn{2}{c|}{ Current caesarean section } \\
\hline Indications & $\mathbf{N}$ & $\mathbf{\%}$ & $\mathbf{N}$ & $\mathbf{\%}$ \\
\hline Fetal distress & 300 & 41.7 & 78 & 24.45 \\
\hline Malpresentation & 211 & 29.3 & 211 & 29.3 \\
\hline Obstructed labor & 45 & 6.3 & 37 & 11.59 \\
\hline Infertility & 25 & 3.5 & 5 & 1.56 \\
\hline Hypertension & 20 & 2.8 & 0 & 0.0 \\
\hline Twin & 19 & 2.6 & 0 & 0.0 \\
\hline Elderly primigravida & 19 & 2.6 & 9 & 2.82 \\
\hline Oligohydramnios and polyhydramnios & 17 & 2.4 & 12 & 3.76 \\
\hline Abruptio placenta & 13 & 1.8 & 19 & 5.95 \\
\hline Failed induction & 12 & 1.7 & 0 & 0.0 \\
\hline Pelvic surgery & 7 & 1.0 & 5 & 1.56 \\
\hline Diabetes mellitus & 5 & 0.7 & 15 & 4.70 \\
\hline Postdate & 5 & 0.7 & 43 & 13.47 \\
\hline Premature mature rupture of membranes & 0 & 0.0 & 8 & 2.51 \\
\hline Bad obstetric history & 0 & 0.0 & 4 & 1.25 \\
\hline Others & 22 & 3.1 & 18 & 5.64 \\
\hline
\end{tabular}

Table 3: Cause of admission to neonatal Intensive care unit.

\begin{tabular}{|c|c|c|c|c|}
\hline Causes & $\mathbf{N}$ & $\%$ & $\begin{array}{l}\text { Successful } \\
\text { VBAC }\end{array}$ & $\begin{array}{l}\text { Unsuccessful } \\
\text { VBAC }\end{array}$ \\
\hline Respiratory distress syndrome & 23 & 48.93 & 6 & 17 \\
\hline Infant of diabetic mother & 12 & 25.53 & 1 & 11 \\
\hline Birth asphyxia & 3 & 6.38 & 0 & 3 \\
\hline Meconium aspiration & 2 & 4.26 & 0 & 2 \\
\hline *Others & 7 & 14.89 & 3 & 4 \\
\hline
\end{tabular}

Note: *Meningomylocel cong, IUGR, Low AP, hemorrhgic disease of new born, small for gestational age 
Table 4: Type of complication occurs after VBAC and repeated caesarean section (CS).

\begin{tabular}{|lllll|}
\hline Type of complications & $\mathbf{N}$ & $\%$ & VBAC & Repeated CS \\
\hline Anemia & 17 & 2.8 & 4 & 16 \\
\hline Difficult intubation & 12 & 1.3 & 3 & 9 \\
\hline Retained placenta & 6 & 0.8 & 6 & 0 \\
\hline Perineal tear & 7 & 1.0 & 4 & 0 \\
\hline Fetal complication & 5 & 0.7 & 2 & 0 \\
\hline Extened episotomy & 2 & 0.3 & 0 & 1 \\
\hline Wound infection & 1 & 0.1 & 1 & 0 \\
\hline Abruptio placenta & 1 & 0.1 & 0 & 1 \\
\hline Uncontrolled hypertension & 1 & 0.1 & & \\
\hline
\end{tabular}

Table 5: Congenital anomalies distribution.

\begin{tabular}{|c|c|c|}
\hline Variables & $\mathbf{N}$ & $\%$ \\
\hline Club foot & 2 & 25 \\
\hline Neural tube defect & 2 & 25 \\
\hline Congenital heart disease & 1 & 12.5 \\
\hline *Others & 3 & 37.5 \\
\hline
\end{tabular}

Note: *Cleft lip, yes low set ear abscent ulna, right conal atresia.

\section{DISCUSSION}

High caesarean section rates are a worldwide problem; a more recent study showed that the highest rates of caesarean section in Derna, Libya due to repeated caesarean section in general hospitals. ${ }^{12}$

Several studies suggest that for appropriately selected women VBAC is safe, even safer than elective repeat caesarean section. However, high caesarean section rates are a worldwide problem. This study was conducted in order to highlight VBAC as a safe delivery method. The aim of this study was to determine the success of vaginal birth after one previous caesarean section. Published literature shows that there has been a $60-80 \%$ success in attempts at vaginal birth after a caesarean section. ${ }^{13}$

The succeed rate of VBAC in present study was $69.3 \%$, this result was comparable with the results of other studies reported by Dhall et al have reported that around $76 \%$ of women with previous caesarean undergoing trial of scar have vaginal delivery, Singh et al in the US report $65 \%$ VBAC and in the UK, it was confirmed that nearly threefourths of women at term undergoing a labor after previous caesarean section achieved a successful vaginal delivery. ${ }^{5,14,15}$ Many women request for repeat elective CS in order to avoid a painful vaginal birth in private hospital. This is mainly due to lack of women information. However, the high success rate of VBAC in our study could be due to good monitoring of labor and the fact that many of women with previous one caesarean section are offered a trial of labor.

Many factors are associated with successful vaginal birth after previous caesarean section. Literature search showed that maternal age of more than 30 years, male fetus, no prior vaginal delivery, augmentation and induction, excessive weight gain during pregnancy and maternal obesity are associated with poor VBAC success rate. ${ }^{16}$ Other factors that affect the probability of successful VBAC are assumed to be gestational age beyond 40 weeks, birth weight greater than $4000 \mathrm{~g}$, and the interval from last delivery of less than 19 months. ${ }^{17}$ In the present study, $30 \%$ of the women where had failed of labor, most of them were older than 36 years and had caesarean section for malpresentation, multiparaous and post-dated.

The results show that the success rate of VBAC with indications for previous caesarean section have been analyzed in several broad categories namely: fetal distress, malpresentation, obstracted labor, primary infertility and severe preclampsia/eclampsia study by Landon et al have report similar results. ${ }^{18}$

In our study, the rate of emergency repeat caesarean section at Al-Wahda hospital was $30.7 \%$ and commonest indication was malpresentation, fetal distress, postdate, obstracted lab and abruptio placenta, which was similar to McMohan et al reported vaginal delivery in $66 \%$ of those with dystocia, $84 \%$ of those with malpresentation and $75 \%$ of those with fetal distress as indication of pervious caesarean section. ${ }^{19}$ However, Phelan et al and Dayal et al reported a lower $(15 \%)$ rate of $\mathrm{FD}$ requiring $\mathrm{CS} .{ }^{20,21}$

The average duration of hospital stay for VBAC was $1.18 \pm 0.52$ days and $3.05 \pm 1.55$ days for repeat CS. Benson et al concluded that the successful VBAC and shorter hospital stay has a positive impact on the psychology of the woman and decreases the total cost of hospitalization. ${ }^{22}$ Similar observations were made by other workers. ${ }^{23,24}$

VBAC has less complications and faster recovery compared with repeated caesarean section. Women should aware of the benefits and harms associated with the mode of birth especially on a trial of labor after one previous 
caesarean birth. In our study, women with a failed trial of labor had an increased rate of anemia and difficult intubation which similar to Sharvit et al, Marshall et al, and Marshall et al. $7,25,26$

High numbers of neonates were admitted to the neonatal intensive care unit following caesarean section delivery and few numbers of neonates were admitted following VBAC. There were statistical differences between caesarean section and vaginal birth. The factors associated with cause of admission to neonatal intensive care unit among VBAC were respiratory distress syndrome similar to Hansen et al. ${ }^{27}$ However, the most common cause of admission among CS delivery was RDS, infant of diabetic mother and birth asphyxia. ${ }^{27,28}$

There were some limitations to this study that should be pointed out. First of all, there were three private hospitals in Derna and it was thought that some of the missing women might have presented at these hospitals and the second, some people migrate from Derna in the second half of 2018 because of military actions.

\section{CONCLUSION}

This study concluded that the high success rate of VBAC could be due to good monitoring of labor and the fact that many of women with previous caesarean section are offered a trial of labor. These findings might help clinicians and women in the decision-making for the mode of delivery when it comes to pregnancy with a previous caesarean section. Women are explained about the option of VBAC and told about the risk associated with a repeat caesarean section, so many caesarean sections can be avoided.

\section{ACKNOWLEDGMENTS}

Authors would like to extend deep thanks to gynecologist residents for collecting data at Al-Wahda hospital Derna, Libya.

Funding: No funding sources

Conflict of interest: None declared

Ethical approval: The study was approved by the Institutional Ethics Committee

\section{REFERENCES}

1. Senturk MB, Cakmak Y, Atac H, Budak MS. Factors associated with successful vaginal birth after cesarean section and outcomes in rural area of Anatolia. Int $\mathbf{J}$ Womens Health. 2015;7:693-7.

2. Brill Y, Windrim R. Vaginal birth after Caesarean section: review of antenatal predictors of success. J Obstet Gynaecol Can. 2003;25(4):275-86.

3. Mozurkewich EL, Hutton EK. Elective repeat cesarean delivery versus trial of labor: a meta-analysis of the literature from 1989 to 1999. Am J Obstet Gynecol. 2000;183(5):1187-97.
4. Betrán AP, Gulmezoglu AM, Robson M, Merialdi M, Souza JP, Wojdyla D, et al. WHO global survey on maternal and perinatal health in Latin America: classifying caesarean sections. Reprod Health. 2009;6:18.

5. RCOG. Green-top Guideline No. 45. Birth after Previous Caesarean Birth, 2015. Available at: https://www.rcog.org.uk/en/guidelinesresearchservic es/guidelines/gtg45. Acessed on 20 July 2021.

6. Sharvit M, Rubinstein T, Ravid D, Maor G, Fishman A, Shental T. Patients with high-risk pregnancies and complicated deliveries have an increased risk of maternal postpartum readmissions. Arch Gynecol Obstet. 2014;290.

7. Nair M, Kurinczuk JJ, Knight M. Establishing a National Maternal Morbidity Outcome Indicator in England: A Population-Based Study Using Routine Hospital Data. PLoS One. 2016;11(4):0153370.

8. American College of Obstetricians and Gynecologists. ACOG practice bulletin no 115: Vaginal birth after previous caesarean delivery. Obstet Gynecol. 2010;116:450-63.

9. Farquhar CM, Li Z, Lensen S, McLintock C, Pollock $\mathrm{W}$, Peek MJ, et al. Incidence, risk factors and perinatal outcomes for placenta accreta in Australia and New Zealand: a case-control study. BMJ Open. 2017;7(10):01771.

10. Silver RM, Landon MB, Rouse DJ, Leveno KJ, Spong CY, Thom EA, et al. Maternal morbidity associated with multiple repeat cesarean deliveries. Obstet Gynecol. 2006;107(6):1226-3.

11. Akker T, Brobbel C, Dekkers OM, Bloemenkamp KWM. Prevalence, Indications, Risk Indicators, and Outcomes of Emergency Peripartum Hysterectomy Worldwide: A Systematic Review and Meta-analysis. Obstet Gynecol. 2016;128(6):1281-94.

12. Elzahaf RA, Ajroud S. Prevalence and indication of caesarean section in Al-Wahda Hospital, Derna, Libya: A retrospective study. Libyan J Med Sci. 2018;2:68-72.

13. Gregory KD, Korst LM, Cane P, Platt LD, Kahn K. Vaginal birth after cesarean and uterine rupture rates in California. Obstet Gynecol. 1999;94(6):985-9.

14. Dhall K, Mittal SC, Grover V, Dhall GI. Childbirth following primary cesarean section--evaluation of a scoring system. Int $\mathbf{J}$ Gynaecol Obstet. 1987;25(3):199-205.

15. Clarke SC, Taffel S. Changes in cesarean delivery in the United States, 1988 and 1993. Birth. 1995;22(2):63-7.

16. Puliyath, G. Vaginal birth after caesarean section (VBAC): a descriptive study from Middle East. Intern J Gynecol Obstet. 2010;12(2):20.

17. ACOG Practice bulletin no. 115: Vaginal birth after previous cesarean delivery. Obstet Gynecol. 2010;116(2):450-463.

18. Landon MB, Hauth JC, Leveno KJ, Spong CY, Leindecker S, Varner MW, et al. Maternal and perinatal outcomes associated with a trial of labor 
after prior caesarean delivery. $\mathrm{N}$ Engl J Med. 2004;351:2581-9.

19. McMahon MJ, Luther ER, Bowes WA, Olshan AF. Comparison of a trial of labor with an elective second cesarean section. N Engl J Med. 1996;335(10):68995.

20. Phelan JP, Clark SL, Diaz F, Paul RH. Vaginal birth after caesarean. Am J Obstet Gynecol. 1987; $157: 1510-5$.

21. Dayal V. Trial of vaginal delivery in cases of single previous caesarean section. J Obstet Gynecol. 1985;35:445-50.

22. Horowitz BJ, Stanley W, Lippmann L. Once a caesarean, always a caesarean. Obstet Gynaec Survey. 1981;36:592-7.

23. Traynor JD, Peaceman AM. Maternal hospital charges associated with trial of labor versus elective repeat cesarean section. Birth. 1998;25(2):81-4.

24. Gibbs CE. Planned vaginal delivery following caesarean section. Clin Obstet Gyn. 1980;23:507.
25. Sharvit M, Rubinstein T, Ravid D, Maor G, Fishman A, Shental T. Patients with high-risk pregnancies and complicated deliveries have an increased risk of maternal postpartum readmissions. Arch Gynecol Obstet. 2014;290(4):629-33.

26. Marshall NE, Fu R, Guise JM. Impact of multiple cesaren deliveries on maternal morbidity: A systematic Review. Am J Obstet Gynecol. 2011;205(3):262.

27. Hansen AK, Wisborg K, Uldbjerg N, Henriksen TB. Risk of respiratory morbidity in term infants delivered by elective caesarean section: cohort study. BMJ. 2008;336(7635):85-7.

28. Tharaux C, Carmona E, Colle MH, Bréart G. Postpartum maternal mortality and cesarean delivery. Obstet Gynecol. 2006;108(3):541-8.

Cite this article as: Ajroud S, Elzahaf RA, Arhaiam FAG. Vaginal birth after previous caesarean section in women at Al-Wahda hospital Derna, Libya. Int J Reprod Contracept Obstet Gynecol 2021;10:4337-42. 